\title{
ESTRATEGIAS PARA EL AFRONTAMIENTO DE CONFLICTOS POR PARTE DEL CONSEJERO EN EL CAMPUS VIRTUAL
}

\author{
Juan Carlos Mojica ${ }^{61}$
}

RESUMEN

Los objetivos de esta investigación corresponden a la necesidad de establecer los diferentes tipos de conflictos que se presentan en estudiantes del campus virtual del curso Proyecto Académico Pedagógico y las estrategias de afrontamiento por parte de la consejería. Asimismo, reflexionar sobre las estrategias asumidas por parte de esta instancia frente a la resolución de conflictos presentados en el campus virtual.

La metodología empleada corresponde a la IAP investigación, acción, participación permanente de la práctica pedagógica. Como resultado del estudio se evidencia la necesidad de desarrollar actividades específicas que conduzcan a lograr el adecuado manejo de emociones y el desarrollo de habilidades como la expresión de sentimientos, el dominio de impulsos y la reducción del estrés que conllevan a una mejor comunicación entre las personas. De igual forma, se sugiere ejecutar un programa para el desarrollo de habilidades comunicativas como la escucha activa que se convierte en una estrategia fundamental para el afrontamiento de conflictos en el campus virtual.

Palabras clave: conflictos, campus virtual, manejo de emociones, programa, desarrollo de habilidad, comunicación.

\begin{abstract}
The aims correspond to the need to establish the different types of conflicts that appear in students of the virtual campus of the course academic pedagogic Project and the strategies of confrontation on the part of the adviser, as well as reflect on the strategies undertaken by the face counseling conflict resolution presented in the virtual campus.

The methodology used corresponds to the IAP research, action and deconstruction of educational practice as income of the study was a clear need to develop specific activities that lead to achieving the proper handling of emotions and skills development as the expression of feelings, pulse domain and stress reduction leading to better communication among people, just as it is suggested to run a program for the development of communication skills like active listening and the activity becomes a coping strategy for the conflict in the virtual campus.
\end{abstract}

Key words: conflicts, virtual campus, academic progress, teaching strategies, counselor.

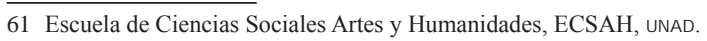




\section{INTRODUCCIÓN}

El conflicto es el resultado de un proceso social, además, de una consecuencia natural de la interacción humana, también es una forma natural con características genéticas, ideológicas, y sociales que se presentan en contextos y situaciones determinadas. El campus virtual establecido como una comunidad de aprendizaje no es ajeno, como cualquier otra comunidad, a la presentación de diversos tipos de conflictos que generalmente ocurren asociados con la percepción que de la situación conflictiva tengan las partes.

El conflicto no necesariamente es negativo. Si se aborda y contribuye con la generación de posibilidades para su transformación y superación con ayuda de las partes o la participación de terceros (en la UNAD puede ser el consejero quien debe desarrollar el papel de mediador, entendido este como un espacio transicional de diálogo cooperativo, en el que al menos 2 partes implicadas en una determinada situación conflictiva y al menos una tercera parte inicialmente no implicada en ella, es decir la persona mediadora, abordan en forma constructiva las diferencias situaciones), que, inmersos en el conflicto, desean tratar y en el que las conversaciones que se producen en el contexto de la mediación no se determinan por la persona mediadora, si no que se realizan por las partes con el fin de llegar a un acuerdo.

Es necesario acotar que cuando las situaciones conflictivas no se presentan directamente entre estudiantes del aula virtual sino entre estudiantes y consejeros deben desarrollarse otras estrategias para el afrontamiento de los mismos.

Como consecuencia, en el ejercicio de investigación acción participativa, efectuada y con el fin de mejorar la práctica pedagógica del consejero, se deben desarrollar estrategias que permitan prevenir y afrontar de forma positiva diferentes conflictos mediante: a) la realización de actividades en las que se debe especificar que conllevan al adecuado manejo de emociones y al desarrollo de habilidades como la expresión de sentimientos, el dominio de impulsos y la reducción del estrés; b) mayor flexibilidad en el manejo del campus, que tenga en cuenta situaciones particulares de aprendizaje como lo cultural y lo ambiental; c) la ejecución de un programa para el desarrollo de habilidades comunicativas como la escucha activa y la capacidad asertiva.

\section{OBJETIVO GENERAL}

Establecer los diferentes tipos de conflictos que se presentan en estudiantes del campus virtual del curso Proyecto Académico Pedagógico y las estrategias de afrontamiento por parte de la consejería.

\section{OBJETIVO ESPECÍFICOS}

Reflexionar sobre las estrategias asumidas por parte de la consejería frente a la resolución de conflictos presentados en el campus virtual. 


\section{METODOLOGÍA}

La metodología empleada para la realización del proceso corresponde a la investigación acción pedagógica, en la cual se efectúa un proceso de construcción y deconstrucción continua que conlleva a una nueva práctica enriquecida.

\section{DISCUSIÓN}

La investigación ha demostrado que es necesario efectuar un adecuado manejo de emociones para contribuir a la disminución del conflicto, ya que las emociones cumplen valiosas funciones que ayudan a sobrevivir avisando de peligros próximos y desencadenando respuestas que incluso en ocasiones pueden salvar la vida, pero que en otras facilitan escenarios de conflicto que generan violencia. Como lo explica Goleman (1996), existen dos mentes; una parte primitiva llamada sistema límbico que gobierna nuestras emociones y otra más reciente llamada neocórtex que creció alrededor del sistema límbico y que gobierna el pensamiento racional. El sistema límbico se especializó en analizar los datos de forma rápida produciendo respuestas en fracción de segundos, que no siempre representan la mayor solución a la situación planteada y por el contrario favorecen la aparición de conflictos que aumentan por este tipo de reacciones como ocurre en las aulas virtuales, en ocasiones, entre estudiantes.

La comunicación entre las personas no es un proceso fácil ya que existen cientos de posibilidades para fallar o errar en la interpretación en un proceso comunicativo, más aún cuando en múltiples ocasiones, cuando estudiantes o consejeros, por ejemplo, no utilizan de forma clara la información lo que ocasiona que el receptor pueda codificar de forma correcta el mensaje e incluso cuando el mensaje es claro para el emisor, el receptor con frecuencia atribuye significados distintos lo que en últimas afecta el proceso comunicativo. Por lo plateado hasta ahora y como lo manifiesta (Barñund, 2008), la comunicación entre 2 o más personas mejorará cuando más parecidas sean las personas en los siguientes grupos: valores, percepciones, asunciones y estilos de comunicación; los valores basados en sistemas de creencias, que se relacionan con lo que se cree correcto o incorrecto moralmente o lo que se cree importante o verdadero. Los sistemas de creencia más arraigadas como los sociales o culturales e incluso religiosos definen la persona y sirven para orientarla en la toma decisiones.

En el campus virtual y de acuerdo con la investigación efectuada, los valores se constituyen en parte importante de los conflictos ya que se siente como amenaza la percepción diferente de eventos relacionados con la cotidianidad como la individualidad o el trabajo colaborativo lo que en últimas facilita la generación de conflictos de carácter negativo. Las percepciones de igual forma juegan un papel determinante en la aparición de conflictos, ya que los individuos experimentan o pueden experimentar de forma diferente un mismo suceso, cuando esto sucede la incomprensión y el conflicto se apoderan de las personas y por ello se hace necesaria la disponibilidad para revisar la situación desde la óptica del otro, desde su punto de vista aceptando como válida esta situación. 
La comunicación y la comprensión del contexto en el que el interlocutor se encuentra inmerso, permite disminuir la posibilidad del surgimiento del conflicto y la escalada del mismo.

\section{RESULTADOS}

El proceso de IAP permitió evidenciar que mediante el desarrollo de actividades especificas puede lograrse el manejo adecuado de emociones y el desarrollo de habilidades como la expresión de sentimientos, el dominio de impulsos y la reducción del estrés, que conllevan a una mayor práctica del ejercicio pedagógico desarrollado por el consejero.

La realización de lecturas integrales de los estudiantes que contemplan aspectos culturales y ambientales al proceso de aprendizaje, permite lograr mejores resultados en los cursos matriculados en el campus virtual, lo que disminuye la presentación de conflictos a este tipo de aula.

La ejecución de un programa para el desarrollo de habilidades comunicativas como la escucha activa y la capacidad asertiva se convierte en una estrategia fundamental para el afrontamiento de conflictos en el campus virtual.

El ejercicio de construcción y deconstrucción permanente de la práctica pedagógica del consejero se convierte en una herramienta fundamental para el mejoramiento del proceso educativo que se realiza.

\section{CONCLUSIONES}

El conflicto es una parte natural de nuestras vidas que aunque a menudo se asocia con hostilidad y violencia, al ser abordado de forma constructiva se convierte en una oportunidad para el crecimiento personal.

Conocer los diferentes tipos de conflicto que se presentan al interior del aula virtual permite comprender los rasgos de personalidad de los implicados, lo que favorece una mejor interacción y consecución de acuerdo que contribuyan al favorecimiento del éxito académico.

El desarrollo de actividades que aportan mayores y más productivos niveles de comunicación se constituyen en una herramienta fundamental en el afrontamiento de aquellos tipos de conflictos negativos.

El aprendizaje de manejo de emociones se da como consecuencia de la capacidad metacognitiva que puesta en práctica se convierte en elemento fundamental para el logro de éxito académico. 


\section{REFERENCIAS BIBLIOGRÁFICAS}

GOLEMAN, Daniel. (1996), La inteligencia emocional. Buenos Aires. Javier Vergara Editor S.A. 1996.

BARNLUND, Dean. Resolución y transformación de conflictos en el ámbito escolar. Fundación Universitaria Iberoamericana FUNIBER. 2008 p. 71.

http://www.inteligencia-emocional.org http://www.infed.org/thinkers/gardner.htm

http://es.wikipedia.org/wiki/Inteligencia_emocional

\section{ANEXOS}

\section{MATRIZ DESCRIPTIVA DEL PROCESO}

\begin{tabular}{|l|l|}
\hline \multicolumn{1}{|c|}{ ANTES } & \multicolumn{1}{|c|}{ AHORA } \\
\hline - Estilo de conflicto \\
\hline $\begin{array}{l}\text { Competitivo "la culpa es suya por no enviar el } \\
\text { trabajo como le dije" }\end{array}$ & $\begin{array}{l}\text { se busca lograr estímulos de conflicto } \\
\text { integrativos. } \\
\text { "la verdad no quise decir eso, discúlpame y } \\
\text { sigamos trabajando. } \\
\text { valorar la diversidad y enfrentar las } \\
\text { diferencias. } \\
\text { Se busca el beneficio mutuo y la unión para } \\
\text { alcanzar metas cooperativas. } \\
\text { Aprender de los errores }\end{array}$ \\
\hline $\begin{array}{l}\text { Manejo de emociones } \\
\text { "sabe que yo envío mi trabajo solo, por que con } \\
\text { usted nadie trabaja" }\end{array}$ & $\begin{array}{l}\text { desarrollo de habilidades como la expresión } \\
\text { de sentimientos, el dominio de impulsos y la } \\
\text { reducción del estrés. } \\
\text { "es que a mi me da rabia que no sean } \\
\text { cumplidos, pero ahora que me explica ya } \\
\text { entiendo". }\end{array}$ \\
\hline $\begin{array}{l}\text { Habilidades comunicativas } \\
\text { Beneficencia en el manejo de habilidades } \\
\text { comunicativas. } \\
\text { "sabe que no me diga mas que yo me di cuenta } \\
\text { que usted no sale con nada". }\end{array}$ & $\begin{array}{l}\text { se espera que se desarrollen mejor las } \\
\text { habilidades comunicativas. } \\
\text { "si señor ahora que lo pienso es mejor así". } \\
\text { escucha activa } \\
\text { tienen en cuenta los canales de la } \\
\text { comunicación emisor, receptor mensaje. }\end{array}$ \\
\hline $\begin{array}{l}\text { Flexibilidad en el manejo del campus y } \\
\text { adaptación a las situaciones de la vida } \\
\text { cotidiana } \\
\text { "La verdad es complicado colaborarle en este } \\
\text { momento por que se cerro la fecha para el } \\
\text { envío de la tarea" }\end{array}$ & $\begin{array}{l}\text { Se esta logrando un proceso de valoración } \\
\text { integral de las situaciones particulares de } \\
\text { aprendizaje. } \\
\text { "Ahora que me explica la situación, } \\
\text { comprendo, tratare de colaborarle con mucho } \\
\text { gusto". }\end{array}$ \\
\hline
\end{tabular}


Revista de InVestigaciones UNAD

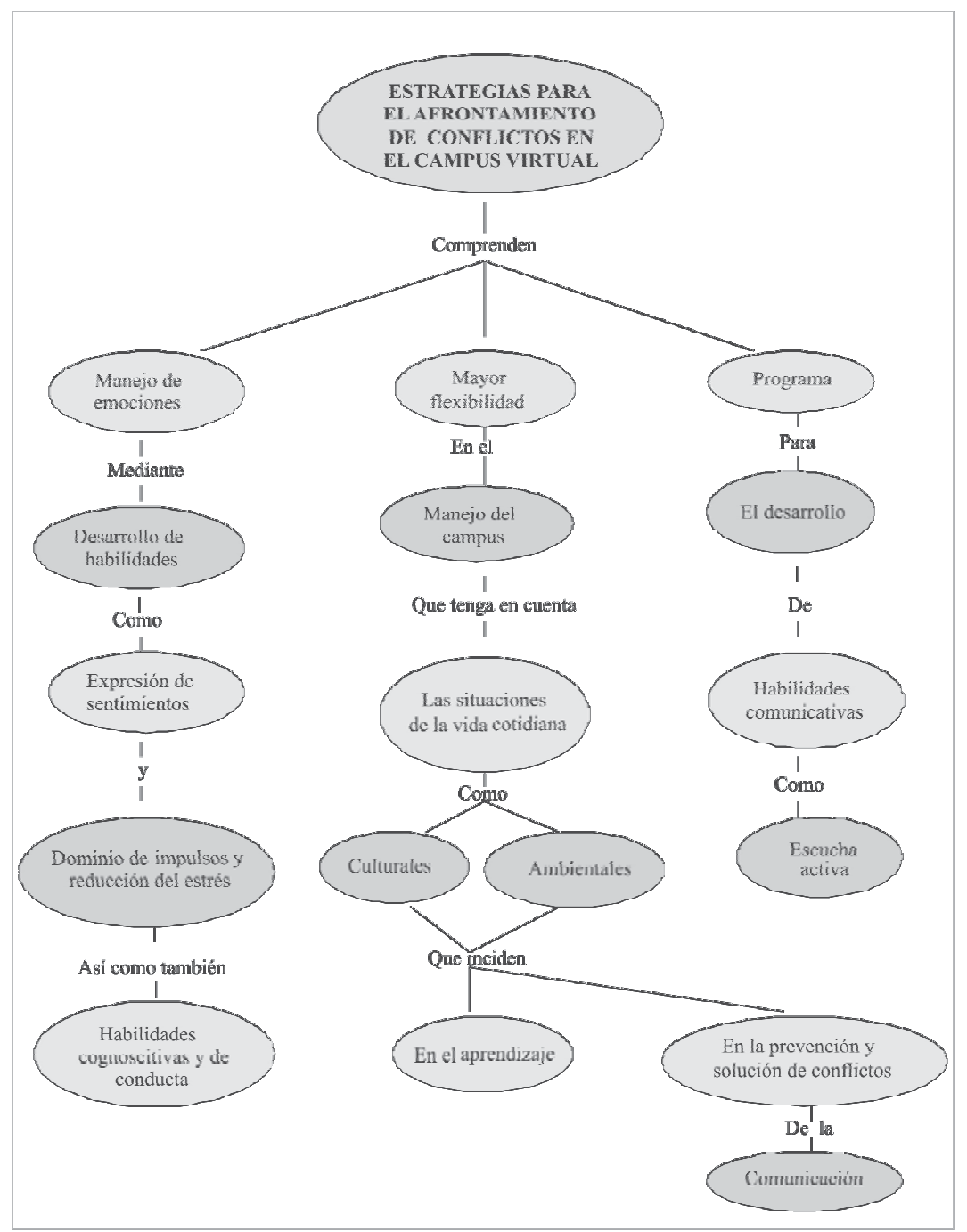

